\title{
Neuronal Degeneration in Canine Narcolepsy
}

\author{
J. M. Siegel, ${ }^{1}$ R. Nienhuis, ${ }^{1}$ S. Gulyani, ${ }^{1}$ S. Ouyang, ${ }^{1}$ M. F. Wu, ${ }^{1}$ E. Mignot, ${ }^{2}$ R. C. Switzer, ${ }^{3}$ G. McMurry, ${ }^{1}$ and \\ M. Cornford ${ }^{4}$
}

${ }^{1}$ Veterans Administration Medical Center Sepulveda and Department of Psychiatry and Brain Research Institute, University of California Los Angeles School of Medicine, Neurobiology Research 151A3, Sepulveda, California 91343, 2Department of Psychiatry and Behavioral Sciences, Sleep Research Center, Richard Lucas/Lab Surge Building, Palo Alto, California 94304, ${ }^{3}$ NeuroScience Associates, Knoxville, Tennessee 37922, and ${ }^{4}$ Department of Pathology, Harbor University of California Los Angeles Medical Center, Torrance, California 90509

Narcolepsy is a lifelong illness characterized by persistent sleepiness, hypnagogic hallucinations, and episodes of motor paralysis called cataplexy. We have tested the hypothesis that a transient neurodegenerative process is linked to symptom onset. Using the amino-cupric silver stain on brain sections from canine narcoleptics, we found elevated levels of axonal degeneration in the amygdala, basal forebrain (including the nucleus of the diagonal band, substantia innominata, and preoptic region), entopeduncular nucleus, and medial septal region. Reactive neuronal somata, an indicator of neuronal pathology, were found in the ventral amygdala. Axonal degeneration was maximal at 2-4 months of age. The number of reactive cells was maximal at 1 month of age. These degenerative changes precede or coincide with symptom onset. The forebrain degeneration that we have observed can explain the major symptoms of narcolepsy.

Key words: narcolepsy; REM sleep; amygdala; basal forebrain; canine; amino-cupric silver; degeneration; cataplexy
Narcolepsy, which occurs at a rate of $0.2-1.6$ per thousand (Aldrich, 1990; Hublin et al., 1994), was first recognized 118 years ago by Gélineau (Passouant, 1976). Its symptoms include excessive daytime sleepiness, hypnagogic hallucinations (dream-like mentation in waking), REM sleep at sleep onset, cataplexy (a loss of muscle tone in waking, usually triggered by sudden, strong emotions), and sleep paralysis (an inability to move at sleep onset or awakening) (Guilleminault, 1994). Narcolepsy has been reported in horses, cattle, and dogs (Mitler et al., 1976; Strain et al., 1984). Canine narcoleptics have been intensively studied. Like human narcoleptics, they are excessively sleepy and have cataplexy. Symptoms in canine and human narcoleptics display a similar response to pharmacological agents (Guilleminault, 1994; Nishino and Mignot, 1997). The cause of narcolepsy is unknown.

Narcolepsy is not a progressive disease, in that once symptoms have become fully established, in both human and canine narcoleptics, they do not become worse (or markedly better) with age. This suggests that narcolepsy may be caused by a transient degenerative process. Examinations of postmortem tissue in human narcoleptics have not produced consistent evidence for degenerative changes. However, symptom onset is typically 50 or more years before autopsy, a sufficient interval for the removal of any debris resulting from degeneration at the time of disease onset. The age of onset of canine narcolepsy is between 1 and 4 months. In the current study, we have used the amino-cupric stain (de Olmos et al., 1994), an extremely sensitive indicator of degenerating neurons and axons (Switzer, 1991; Fix et al., 1996), to test

\footnotetext{
Received June 15, 1998; revised Oct. 2, 1998; accepted Oct. 12, 1998.

This work was supported by the Medical Research Service of the Veterans Administration, United States Public Health Service Grants NS14610 and NS23724.

Correspondence should be addressed to Jerome Siegel, Department of Psychiatry University of California Los Angeles, Neurobiology Research 151A3, Veterans Administration Medical Center, 16111 Plummer Street, North Hills, CA 91343. Copyright (C) 1998 Society for Neuroscience $0270-6474 / 98 / 190248-10 \$ 05.00 / 0$
}

the hypothesis that narcolepsy onset is linked to neuronal degeneration.

\section{MATERIALS AND METHODS}

Eighteen Doberman pinscher dogs, nine narcoleptic and nine age- and breed-matched controls (four male narcoleptics and seven male controls), from six narcoleptic and five normal litters ranging from 1 to 8 months of age were used (Table 1). Control and narcoleptic dogs were reared under similar conditions and never given any pharmacological agents before killing. They were anesthetized with sodium pentobarbital $(50 \mathrm{mg} / \mathrm{kg})$ and perfused with a rinsing solution of $0.8 \%$ sucrose, $0.4 \%$ glucose, and $0.8 \% \mathrm{NaCl}$ in $0.067 \mathrm{M}$ cacodylate buffer, $\mathrm{pH} 7.3$. Fixation was with $4 \%$ formaldehyde in $0.067 \mathrm{M}$ cacodylate buffer containing $4 \%$ sucrose. After the brains were allowed to harden in situ for $24 \mathrm{hr}$, they were removed from the skull and placed in fixative for $7 \mathrm{~d}$.

\section{Amino-cupric protocol}

\section{Embedding and sectioning}

Brains were treated with $20 \%$ glycerol and American Optical dimethylsulfoxide to prevent freeze artifacts. Two half brains (a narcoleptic and control) were embedded side by side, with their medial surfaces aligned using the anterior commissure as a landmark. The block of embedded brains was allowed to cure and then rapidly frozen by immersion in isopentane chilled to $-70^{\circ} \mathrm{C}$ with crushed dry ice. Blocks were mounted on a freezing stage of an American Optical sliding microtome and sectioned coronally at $40 \mu \mathrm{m}$ beginning at the olfactory bulb and proceeding to the spinal medullary junction (i.e., decussation of the pyramids). All sections cut (none were discarded) were collected sequentially into a $4 \times 6$ array of containers. These containers were filled with either standard $10 \%$ commercial, phosphate-buffered formaldehyde or 3.7-4\% formaldehyde buffered with $4.2 \%$ sodium cacodylate, $\mathrm{pH} 7.2$, for sections to be stained with the amino-cupric silver method. At the completion of sectioning, each container held a serial set of one of every 24th section (or, one section every $960 \mu \mathrm{m}$ ). Each of the large sections cut from the block was a composite section holding sections from both of the half brains.

\section{Staining}

Selection of sections for staining. A serial set of every sixth section (a 240 $\mu \mathrm{m}$ interval) was selected for staining with the amino-cupric-silver stain of de Olmos (1994) to reveal disintegrative degeneration. The free- 


\begin{tabular}{|c|c|c|c|c|c|c|}
\hline \multirow[b]{2}{*}{ Age } & \multicolumn{3}{|c|}{ Controls } & \multicolumn{3}{|c|}{ Narcoleptics } \\
\hline & Dog & Sex & Litter & Dog & Sex & Litter \\
\hline 1 & 412 & M & 1 & 316 & $\mathrm{~F}$ & 6 \\
\hline 2 & 402 & M & 2 & 304 & M & 7 \\
\hline 2 & 413 & $\mathrm{M}$ & 3 & 313 & M & 8 \\
\hline 3 & 1760 & M & 4 & 308 & $\mathrm{~F}$ & 9 \\
\hline 4 & $177 \mathrm{P}$ & M & 4 & 305 & $\mathrm{~F}$ & 7 \\
\hline 5 & 178Q & $\mathrm{M}$ & 4 & $180 \mathrm{E}$ & M & 10 \\
\hline 6 & 408 & $\mathrm{~F}$ & 2 & 306 & $\mathrm{~F}$ & 7 \\
\hline 7 & $181 \mathrm{R}$ & $\mathrm{M}$ & 5 & 173 & M & 11 \\
\hline 8 & 400 & $\mathrm{~F}$ & 5 & 303 & $\mathrm{~F}$ & 10 \\
\hline
\end{tabular}

floating sections were taken through the following major steps: preimpregnation, impregnation, reduction, bleaching, and fixing.

The preimpregnation solution contained cupric nitrate, silver nitrate, cadmium nitrate, lanthanum nitrate, neutral red, $\alpha$-amino butyric acid, alanine, pyridine, triethanolamine, isopropanol, and deionized water. After the components were well mixed, the solution was microwaved until it reached $45-50^{\circ} \mathrm{C}$. The solution was left to cool to room temperature, then filtered. The sections were removed from the cacodylatebuffered formaldehyde and rinsed with deionized water. They were then placed into dishes containing the preimpregnation solution and heated in the microwave to $45-50^{\circ} \mathrm{C}$. To allow for cooling, the sections remained in this solution overnight.

The impregnation solution contained silver nitrate, $100 \%$ ethanol, acetone, lithium hydroxide, ammonium hydroxide, and deionized water. The sections were rinsed first in deionized water, second in acetone, and then placed into the impregnation solution. They incubated in this solution for $50 \mathrm{~min}$.

The reducer solution contained $100 \%$ ethanol, formalin, citric acid, and deionized water. The sections were transferred from the impregnation solution into the reducer solution and placed in a water bath with a maintained temperature between 32 and $35^{\circ} \mathrm{C}$. After $25 \mathrm{~min}$ in the reducer solution, the sections were transferred into deionized water rinses, then an acetic acid rinse and back into deionized water.

The bleaching solutions were potassium ferricyanide in potassium chlorate with lactic acid, potassium permanganate with sulfuric acid, and sodium thiosulfate. The sections were rapidly transferred through these bleaching solutions, then fixed in rapid fixer solution for $1 \mathrm{~min} 30 \mathrm{sec}$. The sections were then rinsed in deionized water, mounted on subbed glass slides, and counterstained with neutral red to reveal normal cell bodies.

Using a Neurolucida microscope-computer interface, with bright-field and dark-field illumination, we mapped the entire brain for evidence of axonal debris and reactive neuronal somata. A preliminary analysis was done by J.M.S., who had hemisected and labeled the tissue. When it became apparent that there were consistent differences between the narcoleptic and control data, all the data were systematically analyzed. The data presented herein were all scored by R.N. or by G.M., who were blind to the condition of the animals. Under $2000 \times$ or $4000 \times$ magnification, axonal fragments and reactive neuronal somata were visually identified. An interrupted "string of pearls appearance" characterized axon fragments. These could be followed for considerable differences within sections (Fig. 1). Reactive cells were characterized by a darkened, labeled cytoplasm and often by a shrunken appearance, as illustrated in Figure 1. Axons and cells were counted and mapped onto computer reconstructions of each section.

\section{RESULTS}

Axonal degeneration was elevated in the amygdala, septal nucleus, diagonal band of Broca, and adjacent basal forebrain regions of narcoleptics (Fig. 1a-f). Narcoleptics had significantly higher levels of degeneration across the entire age spectrum than age-matched controls $(F=15.6,8$, and $124 \mathrm{df} ; p<.0001)$. There was no significant difference between amounts of degeneration in male and female dogs within either group, or in the ratio of numbers of degenerating axons or reactive cells in male-female or same sex pairs of narcoleptics and controls. At all ages, and in every pair of narcoleptic-control brains examined, the narcoleptic half had higher levels of degeneration than the control (Wilcoxon test, $t=8.4 ; p<.01)$.

Certain structures contained degenerating axons at 1 month of age (Fig. 2) but not at later ages. At 1 month of age, intense labeling was seen in the medial septal nucleus, diagonal band, fornix, magnocellular preoptic region, substantia innominata, entopeduncular nucleus, and pyriform cortex. Within the amygdala, the basalis magnocellularis, central, lateral, and anterior nuclei were most heavily labeled. Figure 3 shows the distribution of degenerating axons at 6 months of age. At 2-6 months of age, degeneration was seen in medial septal nucleus, diagonal band, amygdala, and pyriform cortex, but not in the fornix, substantia innominata, magnocellular preoptic, or entopeduncular nucleus.

Axonal degeneration was maximal at 1-3 months of age, with the level of degeneration greatly decreased by 8 months of age (Fig. 4). Increased levels of degeneration were present in the septal nucleus, but not in the amygdala, between 6 and 8 months of age (Fig. 4). Despite the role of the brainstem in REM sleep generation (Siegel, 1994) and the involvement of brainstem efferent mechanisms in cataplexy (Siegel et al., 1991), we saw no evidence for elevated levels of degeneration in the brainstem of the narcoleptic dogs at any age.

Stained neuronal somata were seen at increased levels in the amygdala of narcoleptics from 1 to 4 months of age (Fig. $1 g-i$ ). Cell death preceded by reactivity to cupric silver and followed by rapid lysis of the soma may be the primary event, with axonal degeneration and relatively long-lasting axonal debris fields as a consequence (Switzer, 1991; de Olmos, 1994; Fix et al., 1996). Conversely, cells may become reactive to the cupric silver stain during the chromatolytic reaction resulting from axonal loss (Switzer, 1991; de Olmos et al., 1994). The highest levels of reactive cells were at 1 month of age (Figs. 5, 6), with a majority of the labeled cells in the ventral amygdala and pyriform cortex. We stained adjacent sections of tissue from 2-month-old narcoleptics with the TUNEL stain (Oncor), an indicator of apoptosis, but did not see any labeling.

\section{DISCUSSION}

We found that degeneration was present in canine narcoleptics at or shortly before the time of symptom onset. Degeneration was present in areas that have been implicated in response to startle and in sleep control.

No consistent evidence for neuronal or axonal degeneration has been reported in any brain region in human narcoleptics. However, a few cases of "symptomatic" narcolepsy linked to tumors or other lesions have been seen. Most patients with symptomatic narcolepsy have been reported to have diencephalic-basal forebrain-septal nucleus damage, whereas few had any brainstem pathology (Stahl et al., 1980; Erlich and Itabashi, 1986; Aldrich and Naylor, 1989; Servan et al., 1995). A recent report of brainstem lesions in narcolepsy (Plazzi et al., 1996) has been disputed (Bassetti et al., 1997; Frey and Heiserman, 1997). Gross anatomical lesions caused by neoplasms or strokes are absent in the vast majority of human cases (Aldrich, 1990).

The time course of the degenerative process in the narcoleptic dogs paralleled the lower levels of axonal and neuronal degeneration in each brain region seen at the same stage of development in the control dogs, with both peaking at 1-3 months. In the dogs, symptom onset occurs relatively early in life, at 1-4 months of age 

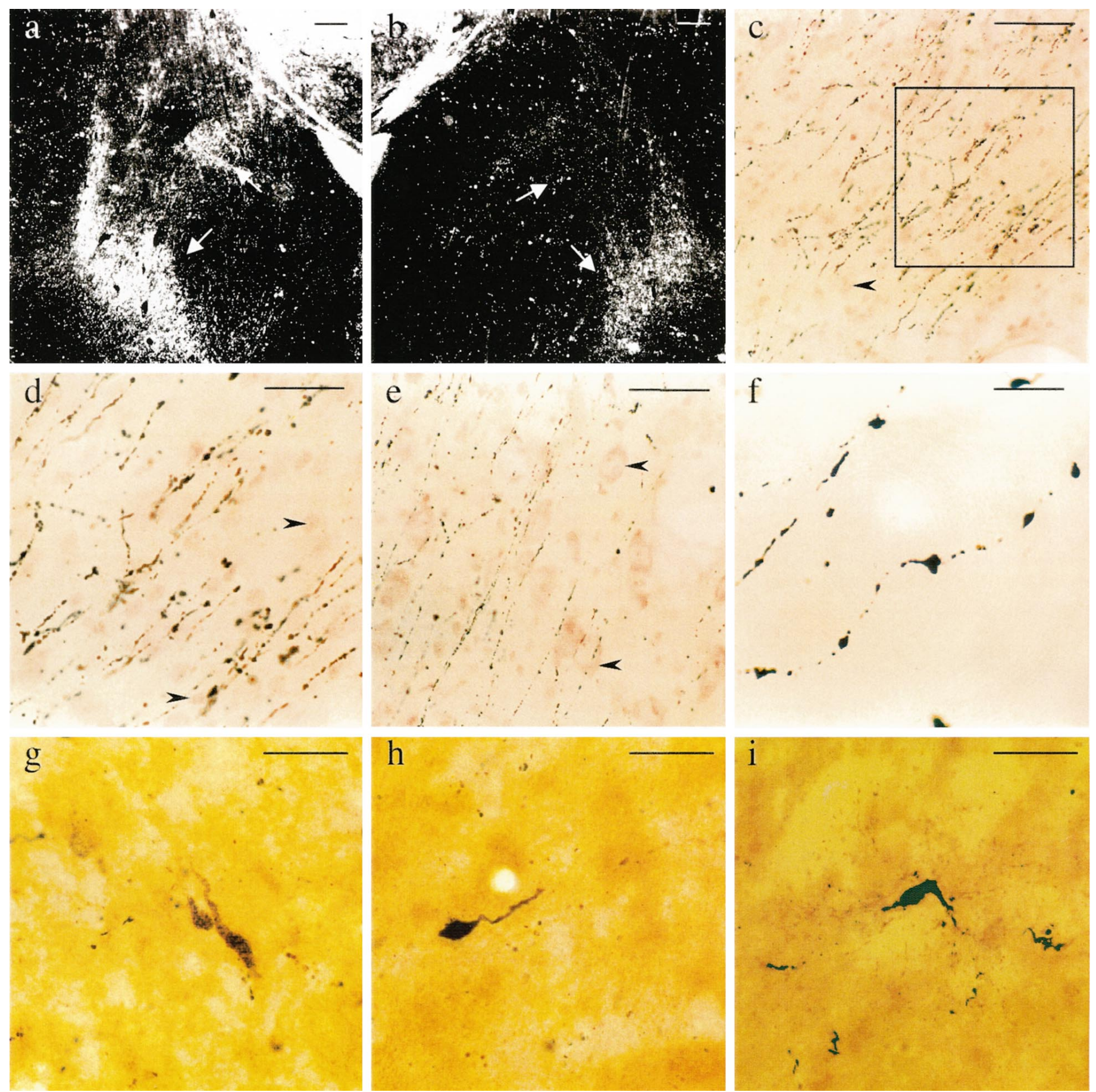

Figure 1. Examples of degenerative changes seen in canine narcolepsy. $a, b$, Low-power dark-field view of amygdala of narcoleptic ( $a$ ) and control ( $b$ ) half brains of 4-month-old dogs. Increased numbers of labeled axons in the narcoleptic dog are visible as brightly illuminated foci in amygdala and pyriform cortex (bottom arrow) and central nucleus of the amygdala [top arrow compared with the same areas in the control half brain (arrows)]. Optic tract is visible in top right of $a$ and top left of $b . c$, Higher magnification of amino-cupric silver-stained sections counterstained with neutral red Niss showing axonal degeneration (black interrupted lines) in pyriform cortex nucleus of 3-month-old narcoleptic. Note several counterstained nonreactive neuronal soma in this and other sections (arrows). $d$ is detail from area indicated in $c . e$. Axonal degeneration in basalis magnocellularis nucleus of 3-month-old narcoleptic. $f$, Detail $(1000 \times)$ of axonal degeneration in medial nucleus of the amygdala of 2-month-old narcoleptic. $g$ - $i$, Reactive neuronal somata in the amygdala and subjacent pyriform cortex of narcoleptic dogs. $g$, A pair of darkly stained cells are visible in the center of a 2-month-old. $h, i$, Labeled cells in the basalis parvicellularis amygdala of a 3-month-old. Scale bars: $a, b, 1 \mathrm{~mm} ; c, e, 50 \mu \mathrm{m} ; d, g-i, 25 \mu \mathrm{m} ; f, 10 \mu \mathrm{m}$.

(Mignot et al., 1993), consistent with the observed neuronal degeneration. Human narcolepsy has been seen in children as young as 3 years (Yoss and Daly, 1960; Billiard, 1985; Kotagal et al., 1990; Challamel et al., 1994) but typically starts in the second or third decade (Aldrich, 1990). Our time course data suggest two possible scenarios for a comparable degenerative process in humans. The first is that degeneration could occur at the age of disease onset with no previous abnormality. The second possibil- 


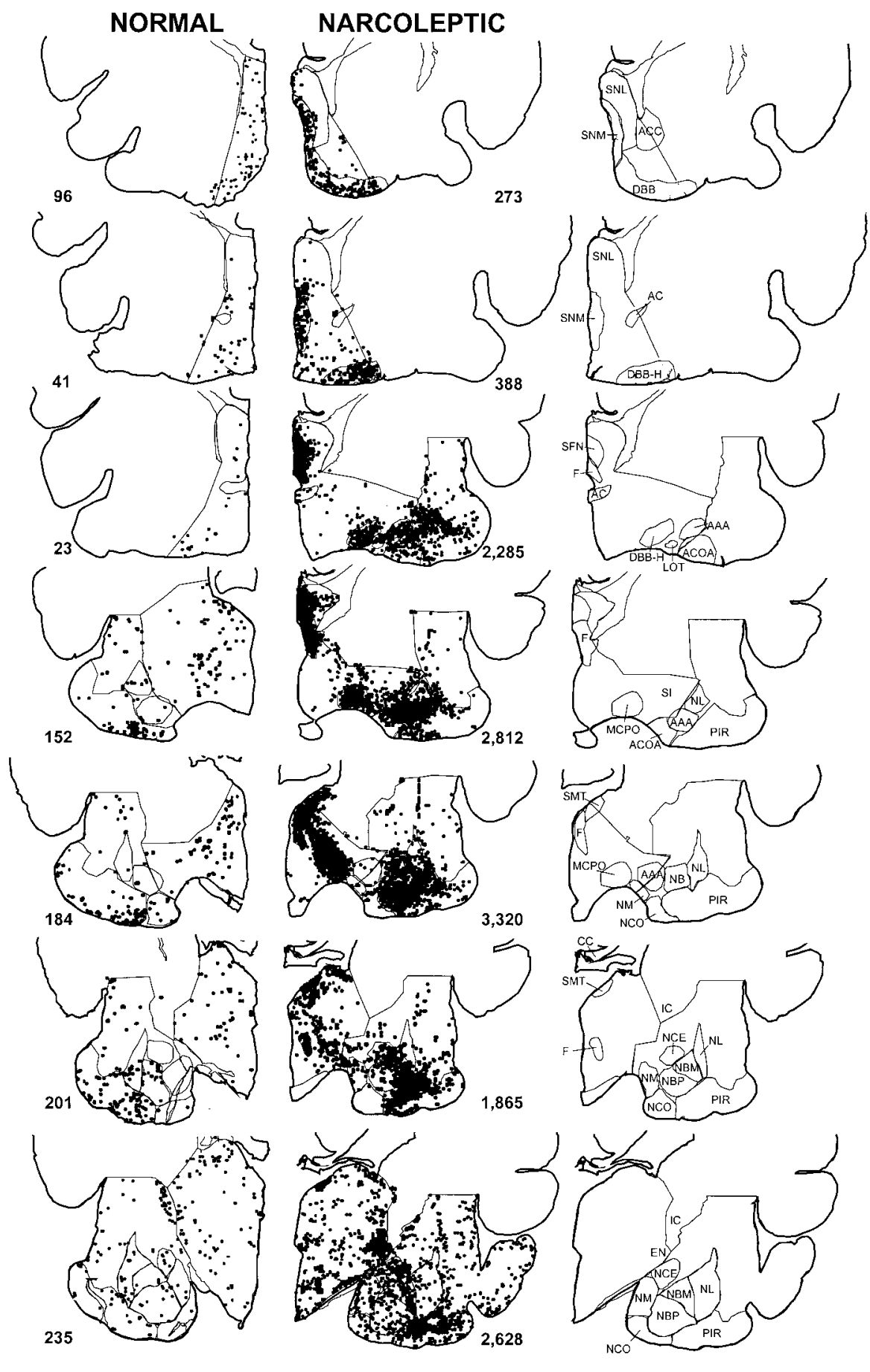

Figure 2. Anatomical distribution of degenerating axons in a pair of half brains from 1-month-old narcoleptic and control dogs processed together. Each dot indicates a degenerating axon fragment. The numbers below each section give the total count of degenerating axons. Sections go from anterior (top) to posterior (bottom). AAA, Anterior amygdala area; $A C O A$, anterior cortical area; $A C$, anterior commissure; $A C C$, nucleus accumbens; $C C$, corpus callosum; $D B B$, diagonal band of Broca; $D B B-H$, horizontal limb of the diagonal band of Broca; $E C$, external capsule; $E N$, entopeduncular nucleus; $F$, column of the fornix; $G P$, globus pallidus; $I C$, internal capsule, $L O T$, lateral olfactory tract: $M C P O$, magnocellular preoptic nucleus; $N B$, nucleus basalis; $N B M$, nucleus basalis magnocellularis; $N B P$, nucleus basalis parvicellularis; $N C E$, nucleus centralis; $N C O$, cortical nucleus; $N L$, lateral nucleus; $N M$, medial nucleus; $P A M$, periamygdaloid area; $P I R$, pyriform cortex; $P U$, putamen; $S I$, substantia innominata; SFN, septofimbrial nucleus; $S M T$, stria medullaris; $S N L$, lateral septal nucleus; $S N M$, medial septal nucleus (nomenclature from Lim et al., 1960). Definitions also apply to Figures 3 and 6.

ity is that degeneration could occur early in development in narcoleptic humans, with some subsequent degenerative or hormonal process triggering the disease at a later age.

The latter time course would resemble that of the degenerative process thought to occur in schizophrenia. Schizophrenia, like narcolepsy, is correlated with degeneration that includes portions of the amygdala and other frontotemporal regions (Bogerts, 1993; Marsh et al., 1994; Nasrallah et al., 1994). The best evidence is that the damage in schizophrenics occurs prenatally or early in development (Bogerts, 1993), as we find in canine narcolepsy.
Like narcolepsy, symptoms of schizophrenia are usually not present in early childhood. Symptom onset in schizophrenics is typically in the second or third decade and, as in narcolepsy, damage does not appear to be progressive (Marsh et al., 1994). Most narcoleptics have hypnagogic hallucinations, a symptom with some resemblance to the hallucinatory mentation of certain schizophrenics. Several cases of schizophrenia coexisting with or misdiagnosed as narcolepsy have been reported (Cadieux et al., 1985; Douglass et al., 1991).

The amygdala is one of the forebrain areas most strongly 


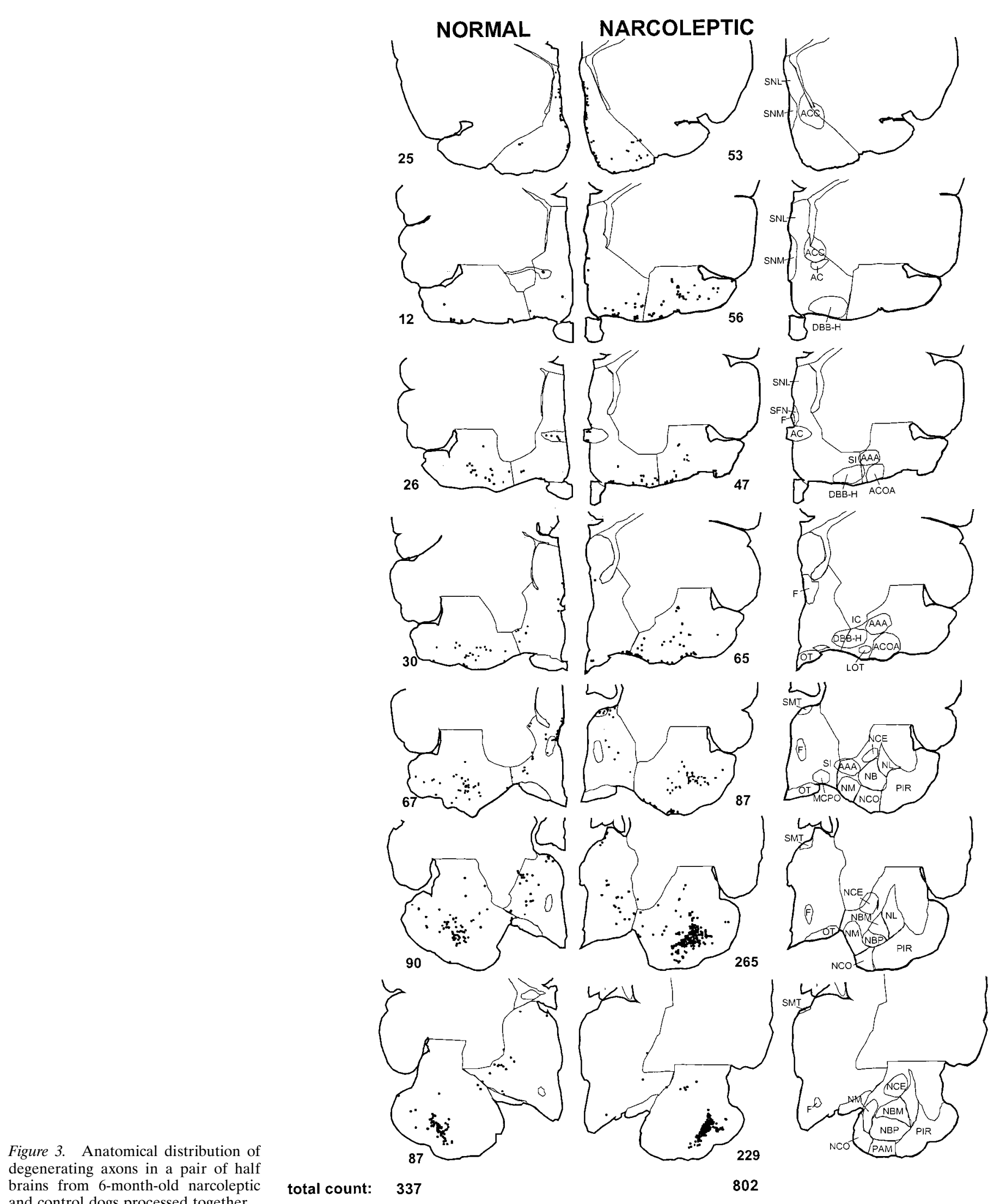



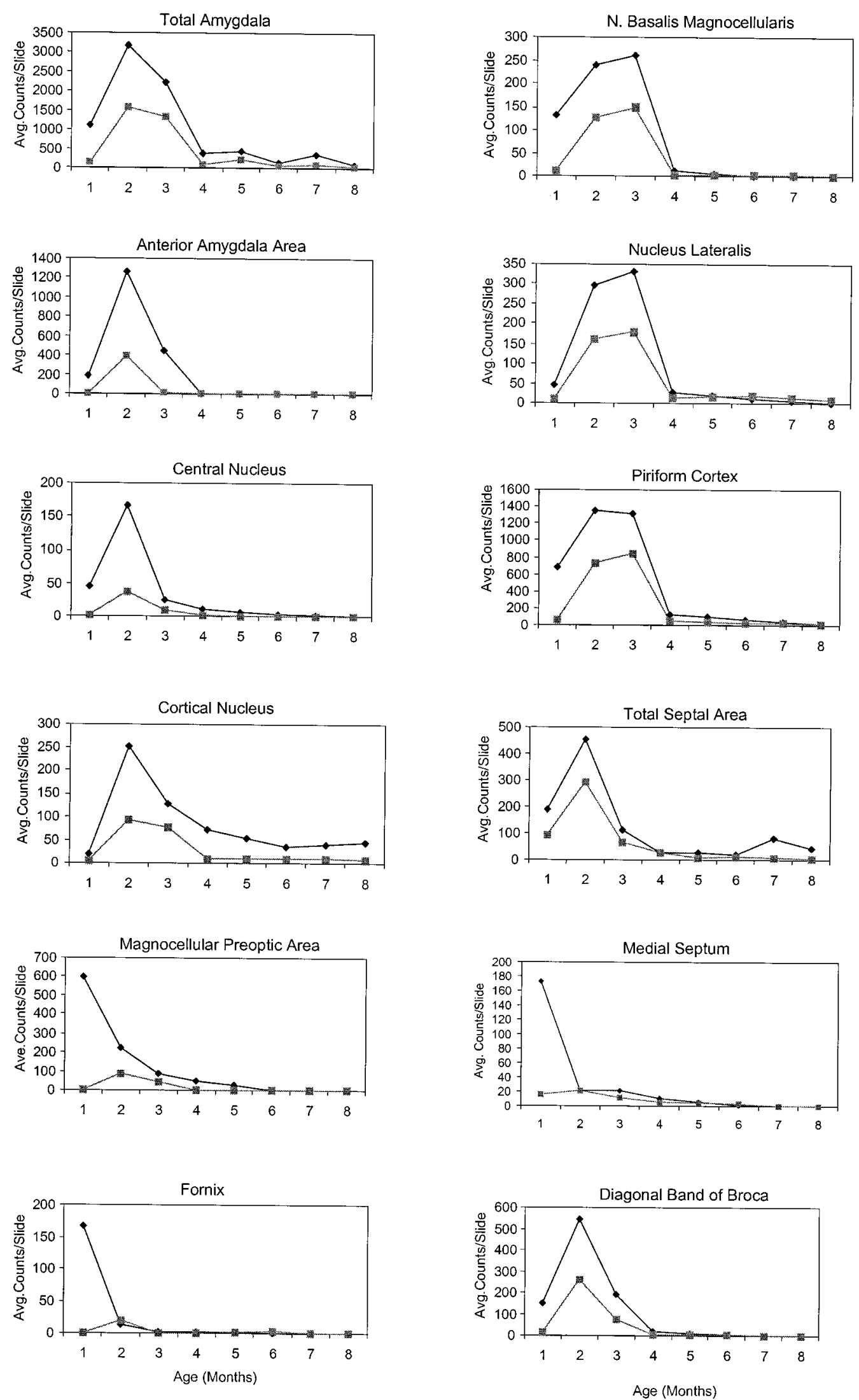

Figure 4. Time course of levels of axonal degeneration with age in narcoleptic and control dogs. All data are from the same group of 18 canines. There was one narcoleptic and one control at each data point except for two of each at 2 months of age. 


\section{Reactive Cells}

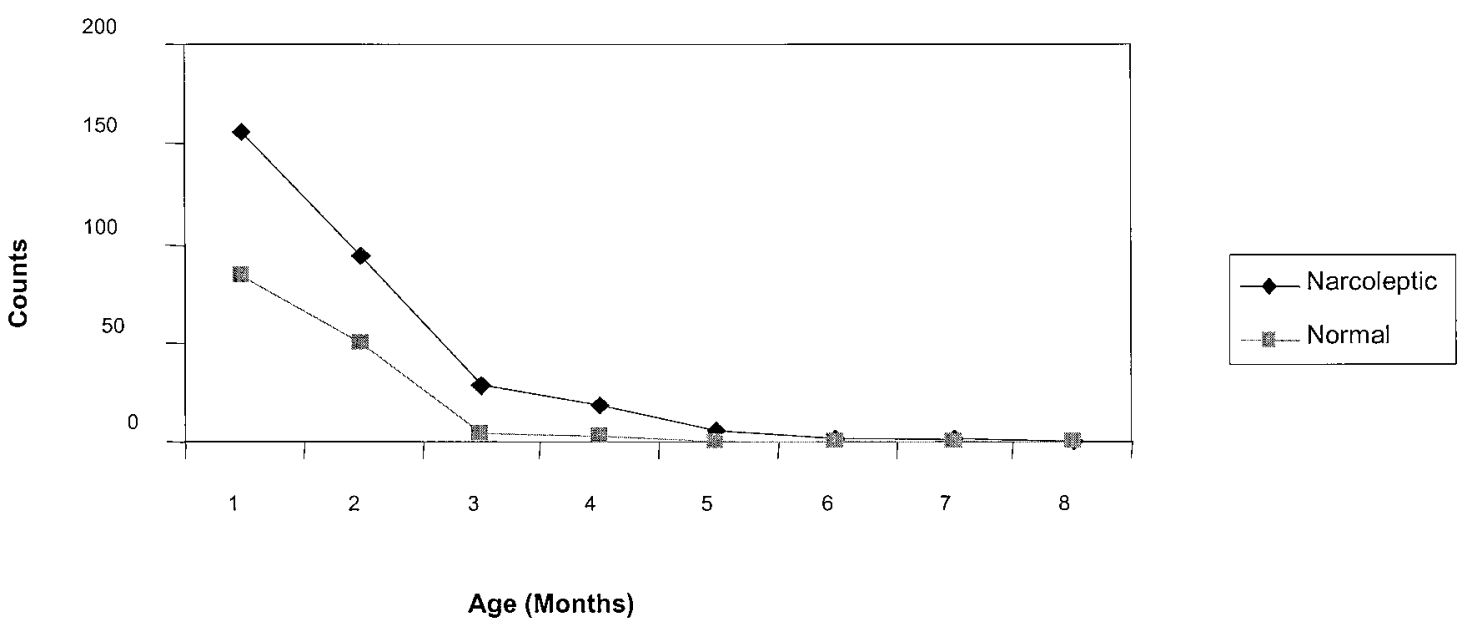

Figure 5. Time course of numbers of reactive cells with age in narcoleptic and control dogs.

activated in REM sleep (Maquet et al., 1996; Nofsinger et al., 1997). Amygdala stimulation in normal cats potently increases REM sleep duration (Calvo et al., 1996). The amygdala is also known to be involved in the elaboration of emotional responses and has a powerful role in the modulation of startle (Campeau and Davis, 1995). There are major projections from the amygdala to the dorsolateral pontine cholinergic and noradrenergic cell regions involved in the generation of REM sleep phenomena (Wallace et al., 1992). We hypothesize that the loss of neurons within the amygdala, basal forebrain, and septal region disinhibits amygdala cells projecting to the brainstem. These disinhibited cells are activated during sudden, strong emotions. This triggers the brainstem motor inhibitory system and inactivates the locus coeruleus (Wu et al., 1998), resulting in cataplexy. It has been shown that activation of the amygdala produces EKG acceleration and apnea (Frysinger et al., 1984), changes that also occur at the onset of cataplexy (Siegel et al., 1989).

The entopeduncular nucleus, like the amygdala, is important in the elaboration of emotional responses and has a particularly important role in the recognition of rewarding events (Hammer et al., 1993; Breiter et al., 1997). Pleasurable stimuli, including food ingestion, the most reliable trigger of canine cataplexy, activate the entopeduncular nucleus (Lidsky, 1975; Schneider, 1987). As in the amygdala, degenerative changes that alter circuitry or disinhibit cells could be responsible for an abnormal output from this region to the amygdala and brainstem regions (Schneider, 1987).

The septal nucleus is known to have important arousal and startle-related functions. Electrolytic lesions of the septum produce a dramatic exaggeration of the startle response (McCleary, 1961). Cholinergic and GABAergic neurons localized to the medial septal region project to limbic structures and produce the theta rhythm in the hippocampus (Vertes and Kocsis, 1997), a rhythm that is prominent in both REM sleep and cataplexy (Wu et al., 1998).

The amygdala, diagonal band of Broca, and magnocellular preoptic region are the major components of the basal forebrain hypnogenic region. Sleep-active neurons, hypothesized to be involved in sleep induction, are localized to this area (Szymusiak and McGinty, 1986b). Stimulation of the ventral amygdala pro- duces EEG synchrony (Kreindler and Steriade, 1964). Stimulation of the preoptic region also induces sleep (Sterman and Clemente, 1962). Lesions of this area produce the most profound insomnia seen after any brain lesion (Szymusiak and McGinty, 1986a). Narcoleptic canines have elevated levels of dopaminergic and noradrenergic receptors in the amygdala, brainstem, and basal forebrain (Mefford et al., 1983; Kilduff et al., 1986). Similar changes are present in human narcoleptics (Aldrich et al., 1992, 1993, 1994). Cholinergic stimulation of the basal forebrain triggers cataplexy in narcoleptic, but not in control canines (Nishino et al., 1995). Disinhibition of the basal forebrain region by loss of local interneurons could produce the major non-REM sleeprelated symptoms of narcolepsy, disruption of nighttime sleep and excessive daytime sleepiness (Aldrich, 1991), as well as the reported changes in receptor levels. Thus, the degeneration we see in amygdala, basal forebrain, and septum are consistent with the EEG, motor, and sleepiness symptoms of narcolepsy.

Human narcolepsy is correlated with the presence of the human leukocyte antigen (HLA) DQB1*0602 genotype (Matsuki et al., 1992). The association of narcolepsy with the major histocompatibility complex marker, HLA-DR2 and DQB1*0602, is one of the highest disease-HLA linkages known (Behar et al., 1995). Most HLA-linked disorders have been shown to be autoimmune in nature (Sinha et al., 1990). Canine narcolepsy is linked to the presence of a marker for an Ig switch-like sequence (Mignot et al., 1991) and enhanced microglial expression (Tafti et al., 1996) at 1-3 months of age. These findings all suggest that immune processes, perhaps related to axonal pruning or cell necrosis, may be linked to narcolepsy onset. Consistent evidence for immune abnormalities in human and canine narcolepsy have not been found, indicating that narcolepsy probably does not involve longterm generalized autoimmune activation (Fredrikson et al., 1990; Mignot et al., 1995). However, autoimmune processes linked to a localized, time-limited degenerative process, preceding symptom onset would be missed by the techniques used to look for autoimmune processes in previous studies. The degenerative changes we have observed could form the link between autoimmune activation and the abnormalities of motor and sleep function that characterize narcolepsy. 
NORMAL

\section{3 months:}
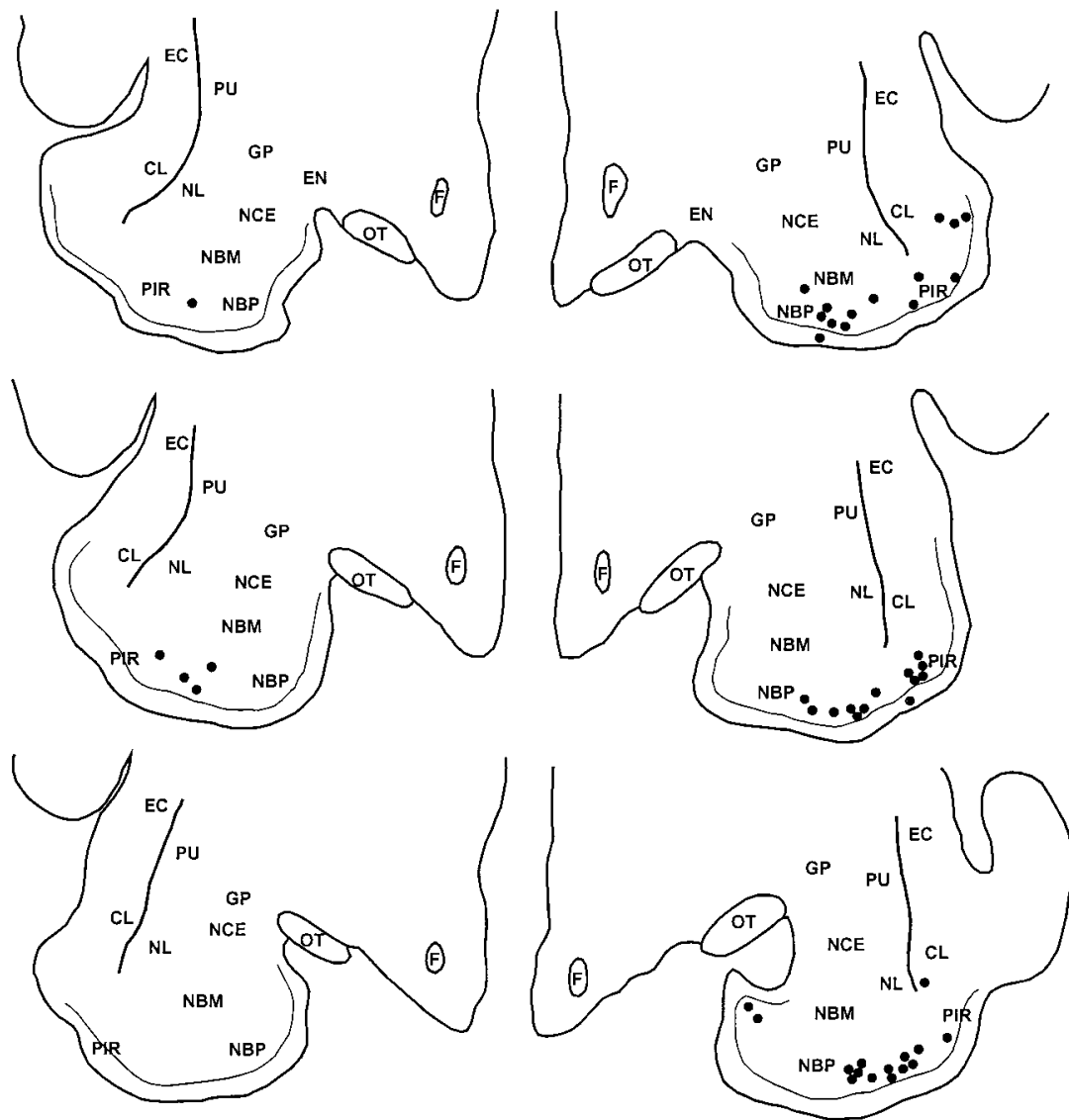

5
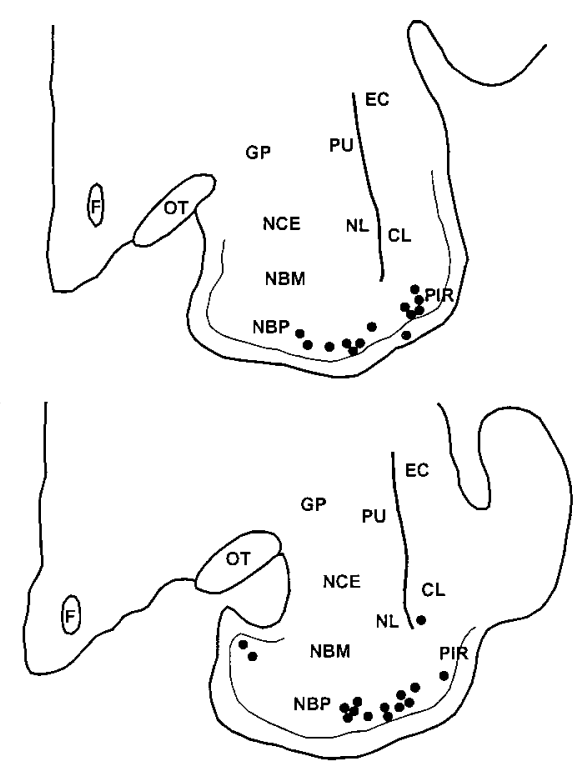

total count:

42

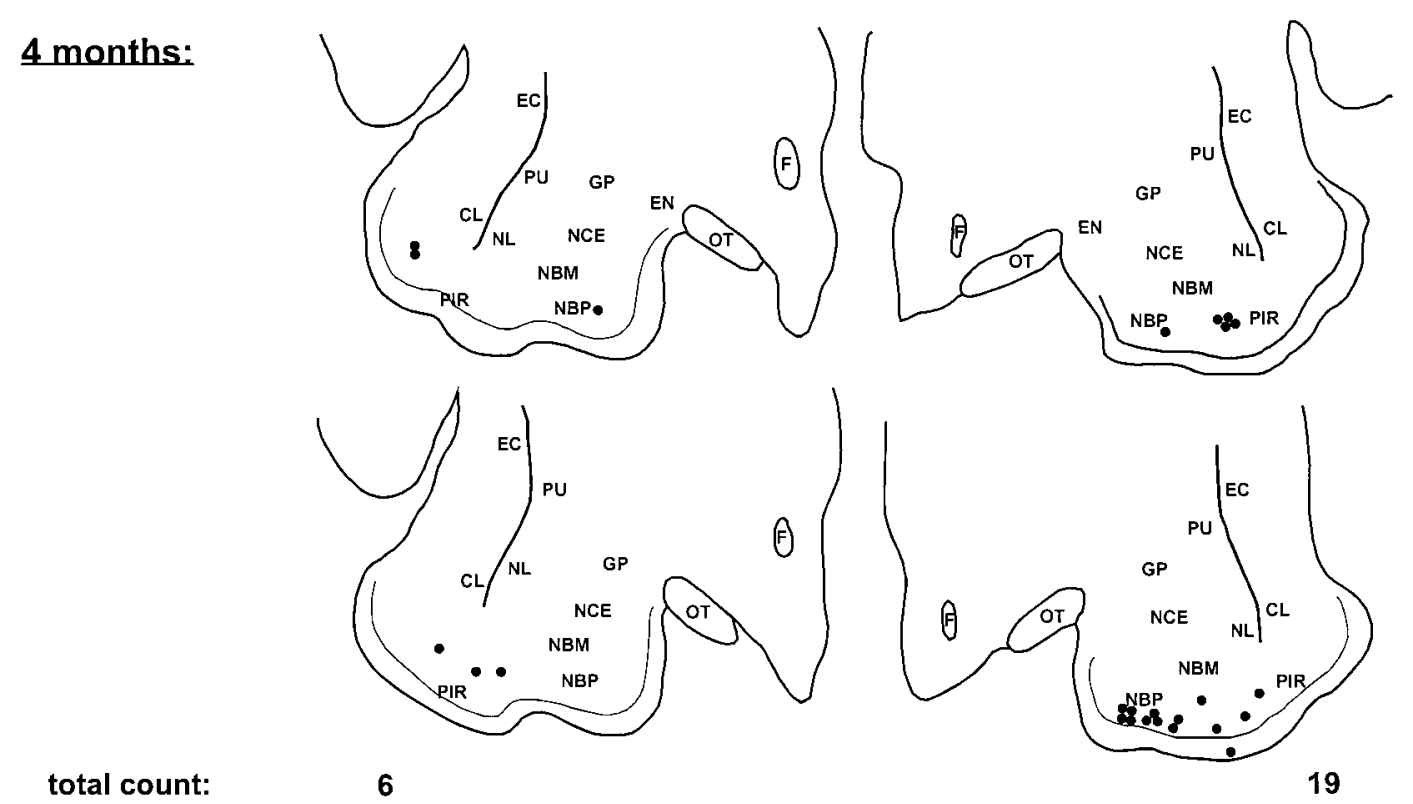

Figure 6. Distribution of reactive neuronal somata in 3- and 4-month-old narcoleptic and normal dogs. Number of reactive somata is indicated below each series. 


\section{REFERENCES}

Aldrich MS (1990) Narcolepsy. N Engl J Med 323:389-394.

Aldrich MS (1991) The neurobiology of narcolepsy. Trends Neurosci 14:235-239.

Aldrich MS, Naylor MW (1989) Narcolepsy associated with lesions of the diencephalon. Neurology 39:1505-1508.

Aldrich MS, Hollingsworth Z, Penney JB (1992) Dopamine-receptor autoradiography of human narcoleptic brain. Neurology 42:410-415.

Aldrich MS, Hollingsworth Z, Penney JB (1993) Autoradiographic studies of post-mortem human narcoleptic brain. Neurophysiol Clin 23:35-45.

Aldrich MS, Desmond T, Frey KA (1994) Muscarinic receptor autoradiography of human narcoleptic brainstem. Sleep Res 23:215.

Bassetti C, Aldrich MS, Quint DJ (1997) MRI findings in narcolepsy. Sleep 20:630-631.

Behar E, Lin X, Grumet FC, Mignot E (1995) A new DRB1*1202 allele (DRB1*12022) found in association with DQA1*0102 and DQB1*0602 in two black narcoleptic subjects. Immunogenetics 41:52.

Billiard M (1985) Narcolepsy. Clinical features and aetiology. Ann Clin Res 17:220-226.

Bogerts B (1993) Recent advances in the neuropathology of schizophrenia. Schizophr Bull 19:431-445.

Breiter HC, Gollub RL, Weisskoff RW, Kennedy DN, Makris N, Berke JD, Goodman JM, Kantor HL, Gastfriend DR, Riorden JP, Mathew RT, Rosen BR, Hyman SE (1997) Acute effect of cocaine on human brain activity and emotion. Neuron 19:591-561.

Cadieux RJ, Kales JD, Kales A, Biever J, Mann LD (1985) Pharmacologic and psychotherapeutic issues in coexistent paranoid schizophrenia and narcolepsy: case report. J Clin Psychol 46:191-193.

Calvo JM, Simon-Arceo K, Fernandez-Mas R (1996) Prolonged enhancement of REM sleep produced by carbachol microinjection into the amygdala. NeuroReport 7:577-580.

Campeau S, Davis M (1995) Involvement of the central nucleus and basolateral complex of the amygdala in fear conditioning measured with fear- potentiated startle in rats trained concurrently with auditory and visual conditioned stimuli. J Neurosci 15:2301-2311.

Challamel MJ, Mazzola ME, Nevsimalova S, Cannard C, Louis J, Revol M (1994) Narcolepsy in children. Sleep 17:S17-S20.

de Olmos JS, Beltramino CA, de Olmos de Lorenzo S (1994) Use of an amino-cupric-silver technique for the detection of early and semiacute neuronal degeneration caused by neurotoxicants, hypoxia, and physical trauma. Neurotoxicol Teratol 16:545-561.

Douglass AB, Hays P, Pazderka F, Russell JM (1991) Florid refractory schizophrenias that turn out to be treatable variants of HLA- associated narcolepsy. J Nerv Ment Dis 179:12-17.

Erlich SS, Itabashi HH (1986) Narcolepsy: a neuropathologic study. Sleep 9:126-132.

Fix AS, Ross JF, Stitzel SR, Switzer RC (1996) Integrated evaluation of central nervous system lesions: stains for neurons, astrocytes, and microglia reveal the spatial and temporal features of MK-801-induced neuronal necrosis in the rat cerebral cortex. Toxicol Pathol 24:291-304.

Fredrikson S, Carlander B, Billiard M, Link H (1990) CSF immune variables in patients with narcolepsy. Acta Neurol Scand 81:253-254.

Frey JL, Heiserman JE (1997) Absence of pontine lesions in narcolepsy. Neurology 48:1097-1099.

Frysinger RC, Marks JD, Trelease RB, Schechtman VL, Harper RM (1984) Sleep states attenuate the pressor response to central amygdala stimulation. Exp Neurol 83:604-617.

Guilleminault C (1994) Narcolepsy syndrome. In: Principles and practice of sleep medicine (Kryger MH, Roth T, and Dement WC, eds), pp 549-561. Philadelphia: W. B. Saunders.

Hammer Jr RP, Pires WS, Markou A, Koob GF (1993) Withdrawal following cocaine self-administration decreases regional cerebral metabolic rate in critical brain reward regions. Synapse 14:73-80.

Hublin C, Partinen M, Kaprio J, Koskenvuo M, Guilleminault C (1994) Epidemiology of narcolepsy. Sleep 17:S7-S12.

Kilduff TS, Bowersox SS, Kaitin KI, Baker TL, Ciaranello RD, Dement WC (1986) Muscarinic cholinergic receptors and the canine model of narcolepsy. Sleep 9:102-106.

Kotagal S, Hartse KM, Walsh JK (1990) Characteristics of narcolepsy in preteenaged children. Pediatrics 85:205-209.

Kreindler A, Steriade M (1964) EEG patterns of arousal and sleep induced by stimulating various amygdaloid levels in the cat. Arch Ital Biol 102:576-586.

Lidsky TL (1975) Pallidal and entopeduncular single unit activity in cats during drinking. Electroencephalogr Clin Neurophysiol 39:79-84.

Lim RKS, Liu C, Moffitt RL (1960) A stereotaxic atlas of the dog's brain. Springfield, IL: Thomas.

Maquet P, Peters JM, Aerts J, Delfiore G, Degueldre C, Luxen A, Franck G (1996) Functional neuroanatomy of human rapid-eye-movement sleep and dreaming. Nature 383:163-166.

Marsh L, Suddath RL, Higgins N, Weinberger DR (1994) Medial temporal lobe structures in schizophrenia: relationship of size to duration of illness. Schizophr Res 11:225-238.

Matsuki K, Grumet FC, Lin X, Gelb M, Guilleminault C, Dement WC, Mignot E (1992) DQ (rather than DR) gene marks susceptibility to narcolepsy. Lancet 339:1052.

McCleary RA (1961) Response specificity in the behavioral effects of limbic system lesions in the cat. J Comp Physiol Psych 54:605-613.

Mefford IN, Baker TL, Boehme R, Foutz AS, Ciaranello RD, Barchas JD, Dement WC (1983) Narcolepsy: biogenic amino deficits in an animal model. Science 220:629-632.

Mignot E, Wang C, Rattazzi C, Gaiser C, Lovett M, Guilleminault C, Dement WC, Grumet FC (1991) Genetic linkage of autosomal recessive canine narcolepsy with a mu immunoglobulin chain switch-like segment. Proc Natl Acad Sci USA 88:3475-3478.

Mignot E, Nishino S, Hunt-Sharp L, Arrigoni J, Siegel JM, Reid MS, Edgar DM, Ciaranello RD, Dement WC (1993) Heterozygocity at the canarc-1 locus can confer susceptibility for narcolepsy: induction of cataplexy in heterozygous asymptomatic dogs after administration of a combination of drugs acting on monoaminergic and cholinergic systems. J Neurosci 13:1057-1064.

Mignot E, Tafti M, Dement WC, Grumet FC (1995) Narcolepsy and immunity. Adv Neuroimmunol 5:23-37.

Mitler MM, Soave O, Dement WC (1976) Narcolepsy in seven dogs. J Am Vet Med Assoc 168:1036-1038.

Nasrallah HA, Skinner TE, Schmalbrock P, Robirtaille PM (1994) Proton magnetic resonance spectroscopy (1H MRS) of the hippocampal formation in schizophrenia: a pilot study. $\mathrm{Br} \mathrm{J}$ Psychiatry 165:481-485.

Nishino S, Mignot E (1997) Pharmacological aspects of human and canine narcolepsy. Prog Neurobiol 52:27-78.

Nishino S, Tafti M, Reid MS, Shelton J, Siegel JM, Dement WC, Mignot E (1995) Muscle atonia is triggered by cholinergic stimulation of the basal forebrain: implication for the pathophysiology of canine narcolepsy. J Neurosci 15:4806-4814.

Nofsinger EA, Mintun MA, Wiseman MB, Kupfer DJ, Moore RY (1997) Forebrain activation in REM sleep: an FDG PET study. Brain Res 770:192-210.

Passouant P (1976) The history of narcolepsy. In: Narcolepsy (Guilleminault C, Dement WC, and Passouant P, eds), pp 3-14. New York: Spectrum.

Plazzi G, Montagna P, Provini F, Bizzi A, Cohen M, Lugaresi E (1996) Pontine lesions in idiopathic narcolepsy. Neurology 46:1250-1254.

Schneider JS (1987) Ingestion-related activity of caudate and entopeduncular neurons in the cat. Exp Neurol 95:216-223.

Servan J, Marchand F, Garma L, Seilhean D, Hauw JJ, Delattre JY (1995) Symptomatic narcolepsy: an anatomic study. Sleep Res 24:345.

Siegel JM (1994) Brainstem mechanisms generating REM sleep. In: Principles and practice of sleep medicine (Kryger MH, Roth T, and Dement WC, eds), pp 125-144. Philadelphia: W. B. Saunders.

Siegel JM, Tomaszewski KS, Fahringer H, Cave G, Kilduff T, Dement C (1989) Heart rate and blood pressure changes during sleepwaking cycles and cataplexy in narcoleptic dogs. Am J Physiol 256:H111-H119.

Siegel JM, Nienhuis R, Fahringer H, Paul R, Shiromani P, Dement WC, Mignot E, Chiu C (1991) Neuronal activity in narcolepsy: identification of cataplexy related cells in the medial medulla. Science 262:1315-1318.

Sinha AA, Lopez MT, McDevitt HO (1990) Autoimmune diseases: the failure of self tolerance. Science 248:1380-1388.

Stahl SM, Layzer RB, Aminoff MJ, Townsend JJ, Fledon S (1980) Continuous cataplexy in a patient with a midbrain tumor: the limp man syndrome. Neurology 30:1115-1118.

Sterman MB, Clemente CD (1962) Forebrain inhibitory mechanisms: 
sleep patterns induced by basal forebrain stimulation in the behaving cat. Exp Neurol 6:103-117.

Strain GM, Olcott BM, Archer RM, McClintock BK (1984) Narcolepsy in a brahman bull. J Am Vet Med Assoc 185:538-541.

Switzer RC (1991) Strategies for assessing neurotoxicity. Neurosci Biobehav Rev 15:89-93.

Szymusiak R, McGinty D (1986a) Sleep suppression following kainic acid-induced lesions of the basal forebrain. Exp Neurol 94:598-614.

Szymusiak R, McGinty DJ (1986b) Sleep-related neuronal discharge in the basal forebrain of cats. Brain Res 370:82-92.

Tafti M, Nishino S, Aldrich MS, Liao W, Dement WC, Mignot E (1996) Major histocompatibility class II molecules in the CNS: increased microglial expression at the onset of narcolepsy in canine model. J Neurosci 16:4588-4595.

Vertes RP, Kocsis B (1997) Brainstem-diencephalo-septohippocampal systems controlling the theta rhythm of the hippocampus. Neuroscience 81:893-926.

Wallace DM, Magnuson DJ, Gray TS (1992) Organization of amygdaloid projections to brainstem dopaminergic, noradrenergic, and adrenergic cell groups in the rat. Brain Res Bull 28:447-454.

Wu MF, Gulyani S, Yao E, Mignot E, Phan B, Siegel JM (1999) Locus coeruleus neurons: cessation of activity during cataplexy. Neuroscience, in press.

Yoss RE, Daly DD (1960) Narcolepsy in children. Pediatrics 25:1025-1033. 